${ }^{1}$ Dr. Khalid Mahmud Medical Officer Dept. of Paediatric Surgery Dhaka Shishu (Children) Hospital

${ }^{2}$ Prof. A R Khan

Professor \& Head

Dept. of Paediatric Surgery

Dhaka Shishu (Children) Hospital

\& Bangladesh Institute

of Child Health (BICH)

3 Prof. Dr. B H Nazma Yasmeen

Professor \& Head

Dept. of Pediatrics

Northern International Medical

College, Dhaka

${ }^{4}$ Prof. M K Islam

Professor \& Head

Dept. of neonatal surgery

Dhaka Shishu (Children) Hospital \& BICH

\section{${ }^{5}$ Dr. Sabbir Karim}

Registrar

Dept. of Paediatric Surgery

Dhaka Shishu (Children) Hospital

\section{Correspondence}

Dr. Khalid Mahmud

Medical Officer

Dept. of Paediatric Surgery

Dhaka Shishu (Children) Hospital

E-mail: drmahmud@yahoo.com

\title{
Classic Swenson abdomino perineal pull through in the treatment of Hirschsprung's Disease - 3 years experience in a tertiary care Paediatric Hospital in Bangladesh
}

\author{
K Mahmud ${ }^{1}$, A R Khan², B H N Yasmeen ${ }^{3}$, M K Islam ${ }^{4}$, S Karim ${ }^{5}$
}

Abstract

Background : Hirschsprung disease (HD)is a common cause of intestinal obstruction. Definitive treatment is to excise aganglionic segment and anastomosis with anal remnant.

Objective : The aim of the study was to analyze the short term outcome of children who have undergone the Classic swenson abdominoperineal pull through operation in the treatment of Hirschsprung's disease.

Methods : This Prospective study had been carried out in the department of paediatric surgery, Dhaka shishu (Children) Hospital during the period of January 2013 to January 2016. Total 50 patients with Hirschsprung's disease with or without colostomy except total colonic aganglionosis were included in this study.We also excluded those patients with major co-morbidities and patients who did not agree to close stoma within 12 weeks of pull through. Consideration was given to postoperative complications/Cuff lanastomotic/pelvic abscess, wound infection, anastomotic leakage,fecal incontinence, urinary incontinence, mortatality), operation time and post operative hospital stay and as well as the short term outcome.

Result : Among the study population $36(72 \%)$ were male and $10(28 \%)$ were female with a male female ratio of 2.5:1. Mean age at presentation was $17.96 \pm 12.05$ months. Thirty eightpatients had diverting colostomy and underwent staged procedure.On the other hand 12 patients had no colostomy and underwent single stage procedure.Four patientsdeveloped anastomoticabcess, 3patients developed urinary incontinence, 4 fecal incontinence and 2 patients developed post operative intestinal obstruction. The mean Operation time was $114.14 \pm 13.02$ minutes and mean hospital staywas $6.18 \pm 1.83$ days.Thirty seven patients were discharged without any complications.

Conclusion : The Classic Swenson's procedure is an effective procedure in the treatment of HD .

Key words : Hirschsprung disease, Classic swenson pull through.

Northern International Medical College Journal Vol. 8 No. 01 July 2016, Page 185-188

\section{Introduction}

Hirschsprung's disease is one of the most common surgical diseasein paediatrics with an incidence of approximately 1 in 5000 live births characterized by the absence of ganglion cells in the myenteric and submucosal nerve plexuses of the distal intestine. ${ }^{1-3}$ Because these cells are responsible for normal peristalsis, patients with Hirschsprung disease present with functional intestinal obstruction at the level of aganglionosis. The absence of ganglion cells or aganglionosis starts at the distal bowel beginning at the internal anal sphincter and extending proximally for various length(in $5 \%$ to $10 \%$ of cases can involve the entire colon or even a significant amount of the small intestine). ${ }^{4,5}$ The initial attempt to cure the disease were a diverting colostomy suggested by various authors. ${ }^{4}$ The procedure relieved the symptoms butrecurred after closure of colostomy.

Swenson pull through was the historic breakthrough in the understanding of pathogenesis and treatment of HD. The procedure, soon became popular as Swenson's procedure, brought a realistic hope that children with HD can be cured. ${ }^{6}$ Barium enema may help in diagnosis but transition zone may not be obvious within 3 months of age. ${ }^{7}$ Rectal biopsy remains the gold standard in confirming the HD. The first successful tratment HD was undertaken over sixty years ago by Over Swenson. ${ }^{8}$

Since then the operative management of HD has evolved dramatically, from, an endorectal dissection(soave), ${ }^{9}$ a retrorectal pouch procedure(duhamel) ${ }^{10}$ and a low anterior resection(Rehbein), ${ }^{11}$ to more recently a primary 
repair ${ }^{12,13}$ that can be done transanally ${ }^{14,15}$ and using laparoscopic technique ${ }^{16}$ tofull thickness rectosigmoid dissection (swenson). ${ }^{17}$ On this background different procedures are being practicedin Bangladesh. In our institution we demonstrated our experience with Classic Swenson pull through dissection for the treatment of HD over a period of 3 years.

\section{Materials and Methods}

The prospective study was conducted in the department of paediatric Surgery, Dhaka Shishu (Children) Hospital during the period of January 2013 to January 2016 after getting ethical permission from ethical comittee of Bangladesh Institute of Child health (BICH). Total 50 diagnosed HD patients with or without colostomy except total colonic aganglionosis and agreed to close colostomy within 12 weeks of pull through operation were included. We also excluded those patients who had major comorbidities (e.g. major Congenital Heart Disease, multiple congenital anomalies etc.) and were not interested to include in the study.All 50 patients of diagnosed HD were operated by Classic Swenson abdominoperineal pullthrough technique.

After getting written concentfrom parents, all data were collected from preformed questionnire. Data included relevant history, clinical features of the patients, results of contrast enema demonstrating transition zone, histopathology report of rectal biopsy, operative findings, post operative management and follow up at 2nd, 4th, 8th and 12th weeks following operations to see the wound infection, fecal incontinence, urinary incontinence, anastomotic abscess/cuff abscess/ pelvic absces. Data of operation time and post operative hospital stay were also collected. All Collected data were compiled and arranged in a systematic manner.

\section{Operative Technique}

Mechanical bowel preparations along with rectal irrigations are recommended. Prior to Operation. A total body preparation from the nipples to the toes and urinary catheterization is performed.

The operation was originally done through a laparotomy, with the anastomosis being performed from a perineal approach after eversion of the aganglionic rectum. Coloanal anstomosis was done $1 \mathrm{~cm}$ proximal to dentate line( picture:1B).Dissection continued up to the tip of the coccyx (picture: $1 \mathrm{~A}$ ). Then the dissected aganglionic gut was pulled through the anus in everted fashion. Last of all the healthy ganglionic gut was pulled through the aganglionic gut keeping a seromuscular cuff measuring $1 \mathrm{~cm}$ anteriorly and $0.5 \mathrm{~cm}$ posteriorly(picture:1C)

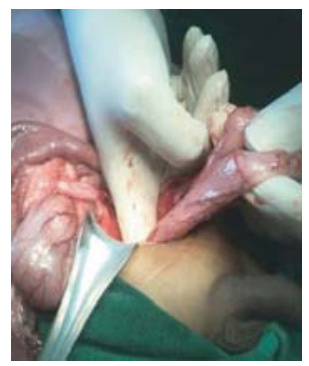

(A)

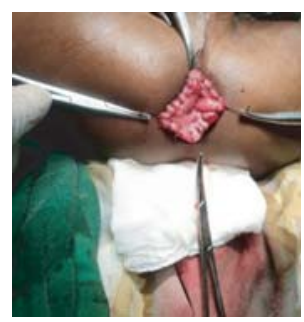

(C)

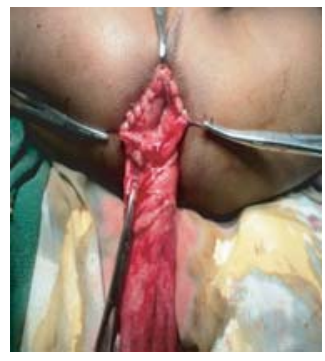

(B)

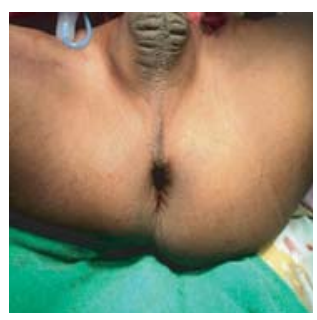

(D)

\section{Picture I :}

Showing steps of classic abdominoperineal Swenson Pull through. (A) Identification of normal colon with mobilization.

(B) Colo anal anastomosis. (C) Anastomosis complete.

(D) Reposition of anastomosis.

\section{Results}

After employing inclusion criteria 50 patients were enrolled, with age at the time of operation ranging from 1day to 96 months withmean was $17.96 \pm 12.05$ months. There were 36 male (72\%) and $14(28 \%)$ female patients and a male female ratio of 2.5:1.Age and sex distribution has shown in Table I.

Table-1 : Age and sex distribution among study population $(n=50)$

Age

Range

Mean \pm SD

1 day- 96 months

Sex

Male 36(72\%)

Female

M:F Ratio

The clinical presentations were shown in Table-2. Chronic constipation and abdominal distention were common. History of delayed passes of meconium was present in $38(78 \%)$ patients. All patients had features of intestinal obstruction on plain abdominal radiograph. Contrast enema was performed in all patients and demonstrated transition zone.

Thirty (60\%) patients had colostomy prior pull through operation. Twenty five (83\%) were sited in right transeverse colon and remaining $5(17 \%)$ were sited in sigmoid colon. Eighteen (60\%) had diverting colostomy and remaining 12 (40\%) had loop costomy. 


$\begin{array}{lc}\begin{array}{l}\text { Table-II : History and Clinical Presentation in children with HD } \\ \text { Clinical features }\end{array} & \text { Frequency(\%) } \\ \text { Delayed passes of meconium } & 38(78 \%) \\ \text { Chronic constipation } & 32(64 \%) \\ \text { Abdominal distention } & 34(68 \%) \\ \text { Vomiting } & 8(16 \%) \\ \text { Enterocolitis } & 5(10 \%) \\ \text { Failure to thrive } & 2(4 \%) \\ \text { Fecoloma } & 4(8 \%)\end{array}$

The definitive Swenson procedure was done at median age of 8 months with a range of 42 weeks to 96 months. Twenty(40\%) patients had primary pullthrough without colostomy. About 93\% of the patients had their transition zone restricted to rectosigmoid area. (Table-III)

$\begin{array}{lc}\text { Table III : Level of transition zone determined by contrast enema } \\ \text { Site of transition zone } & \text { Frequency(\%) } \\ \text { Rectosigmoid } & 40(80 \%) \\ \text { Descending colon } & 6(12 \%) \\ \text { Transverse colon } & 2(4 \%) \\ \text { Spleenic flexure } & 1(2 \%)\end{array}$

The mean operation time from incision to dressing was $115.16 \pm 16.17$ minutes the mean hospital stay was $7.15 \pm$ 1.85days.(Table- IV)

Table-IV: Total time of operation and hospital stay of the study population

Features

$$
\begin{gathered}
\text { Operation Time (min) } \\
\text { Mean } \pm \text { SD } \\
\text { Range } \\
\text { Hospital Stay (day) } \\
\text { Mean } \pm S D \\
\text { Range }
\end{gathered}
$$

Classic Swenson abdomino
perineal pullthrough
$115.16 \pm 16.17$
$90-135$
$7.15 \pm 2.86$
$7-21$

Postoperative complications were evaluated immediately and on 2nd, 4th, 8th and 12th weeks following operations to seeshort term outcome of children who have undergone the Classic swensonabdominoperineal pull through operation in the treatment of Hirschsprung's disease.Five patients needed perioperative blood transfusion. Two patients developed anastomotic abscess and resolved by antibiotic therapy and drainage, 2 patients developed pelvic abscess which needed laparoscopic drainage, 1 patient developed faecal incontinence and no patient developed urinary complications. One patient who had primary pullthrough needed re-do pull through due to residual aganglionosis.Only one patient developed post operative intestinal obstruction due to bands and adhesion which resolved after conservative management. One patient died after multiple procedures, most probably due to sepsis as per clinical and biochemical evidences. He had post operative anastomotic leakage. Total 35 patients (70\%) had good surgical outcome (Fig.-2)

In $42(96 \%)$ patients, there were continence to flatus and faeces. Frequency varied from once tosix times daily. Two(4\%) cases were occational soiling which improved over time and one (2\%) patient developed night time incontinence.

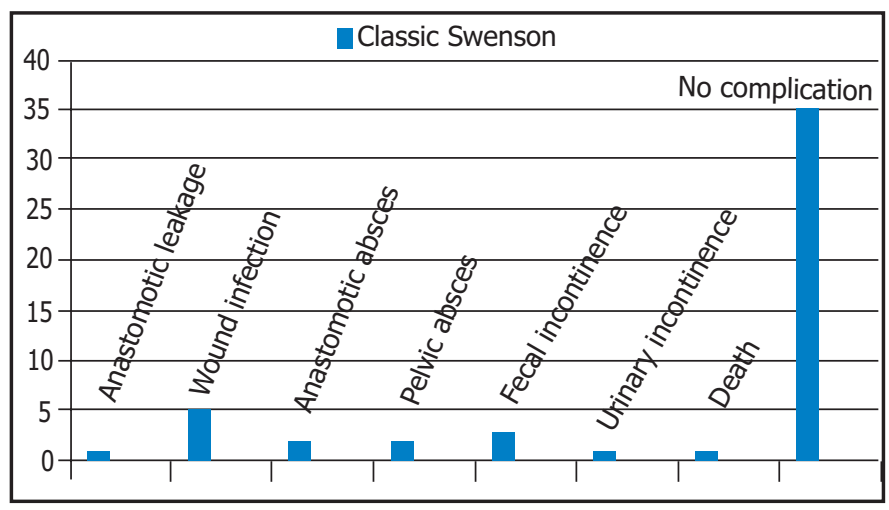

Fig.I : Total outcome of the study

\section{Discussion}

Hirschsprung's disease was originally uncovered by Dr. Over Swenson and the original operative procedure, described by Dr. Swenson and Bill in $1948 .^{2}$ and since then different techniques were adopted to treat Hirschsprung's disease. ${ }^{5-11}$ This study evaluated the short term outcome of Swenson procedure for the treatment of HD in Dhaka Shishu (children) Hospital in Bangladesh. Currently transanal procedure is preffered to classical Swenson as transanal procedure is associated with less morbidity. Swenson procedure is still prefered technique in our hospital.

In this study male was predominant than female. The male female ratio was $3: 1$ which was very close to another study. ${ }^{1}$

Regarding operation time, the mean operation time in this study was $68.46 \pm 29.03$ minutes which was more or less similar to the study done by Leily $M$ et al.where the mean operation time was $134.3 \pm 51.4$ minutes. $^{24}$

Postoperative hospital stay was ranges from 4 to 6 days and mean was $5.04 \pm .43$ days. In the study 1 patient was discharged on request on 4 th POD that makes the range 4 to 6 days. After removal of the catheter on 3rd POD, patients who developed retention, burning micturation and fever was kept admitted for more days. Moreover less wound infection and less urinary complications lessen postoperative hospital stay in the study population.

In this study at follow up on 12th week we found $35(70 \%)$ patients had good postoperative outcome i, ethese patients werewithout complications. In the study of Sowande OA et al 2011 , postoperative good outcome was in $76 \%$ which was also similar to our study. ${ }^{2}$ Normal urinary and faecal continence is the primary goal which led to different modification of this procedure.Urinary continence is satisfactory in most patients in this series. The incidence may vary from $1 \%$ to as high as $37.7 \% .{ }^{19-20}$ In this study only 3 patients complained of soiling 
after surgery and 1 patient developed urinary incontinence. Though incontinence can notbe judged beyond 3 years of age. In this study patients having urinary dribbling even after last follow up (at 12 weeks) were noted as incontinence. Probably the pelvic dissection leads to injury to the nerve plexus around the bladder and causes incontinence. ${ }^{21-22}$ In our study, we noticed 4 patients had urinary dribbling after catheter removal, but in subsequent follow up on 8th week urinary dribbling of 3 patients resolved and 1 persisted up to 12th week. In the study of Zhang SC et al. ${ }^{23}$ showed $3.1 \%$ patients developed urinary incontinence, but he judged it after a long follow up more than 3 years. So we have to follow up more to conclude finally about urinary incontinence.

In our study 2 patients developed anastomotic abscess and 2 patients developed pelvic abscess. We performed 2 stage operations by exteriorising the labelling colostomy for that 4 patients who developed anastomotic abscess and pelvic abscess. Moreover mean age of the patients who developed abscess was 24.75 months.In these patients per operatively we found sign of inadequate decompression of ganglionic segment. Probably these things played role in more abscess formation. ${ }^{23}$ In the study of Fonkalsrud E.W et.al these complication occur in $10.52 \%$ which was higher than our study. ${ }^{22}$

The operative mortality associated with Swenson pull through is low in many series and ranges from $0-2.5 \%$. In this study mortality rate is $2 \%$ which is within range of other studies. ${ }^{24-25}$

\section{Conclusion}

In conclusion, our short term results are quite promising. Classic Swenson procedure is a feasible for short segment as well as long segment HD though it has some complications still it has some role in the management of HD in children especially in our setup.

\section{References}

1. Jacob CL. Hirschprung disease. in : JA O'Neil, MI Rowe, JA Grossfield, EW Fankalsrud, AG Coran, editors.Pediatric Surgery, $7^{\text {th }}$ edn, Missouri: Mosby year book, 2004;2: 1870-95

2. Sowande $O A$, Adejuyigbe 0 . Ten years experience with the Swenson procedure in Nigerian children with Hirschsprung's disease. African journal of paediatric surgery.2011;8(1):44-48

3. Badner JA, Sieber WK, Garver KL,Chakravarti A. A genetic study of hirschprung's disease.Am J Hum Genet 1990;46:568-80

4. Swenson 0 ., Bill AH. Resection of rectum and rectosigmoid with preservation of the sphincter for benign spastic lesions producing megacolon: An experimental study. J Surg1996; 24: 212-20.
5. Stewart DR, Von Allmen D,The genetics of Hirschsprung's disease. Gastroenerol Clin North Am 2003;32:819-37

6. Skaba R. Historic milestones of Hirschsprung's disease (commemorating the 90th anniversary of Professor Harald Hirschsprung's death). J Pediatr Surg; 2007;42: 249-51.

7. Swenson 0. Partial internal sphincterotomy in the treatment. Ann surg1964;160:540-50

8. Swenson 0 ., Bill $A H$. Resection of rectum and rectosigmoid with preservation of the sphincter for benign spastic lesions producing megacolon: An experimental study. J Surg; 1948; 24: 212-20

9. Soave F. A new operation for the treatment of Hirschsprung's disease.J Pediatr Surgery.1964; 56:1007-14

10. Duhamel. B. A new operation for the treatment of Hirschsprung's disease. Arch Dis Child; 1960; 35:38-39.

11. RehbeinF, Von Zimmermann H. Results with abdominal resection in Hirschsprung's disease. Arch Dis Child.1960; 35:29-37

12. So HB, Schwartz DL, Becker JM,et al. Endo rectal pull through without priliminary colostomyin neonates with Hirschsprung's disease. J pediatr surg 1980; 15:470-71

13. Teitelbaum $D H$, Coran $A G$, Primary pull through for hirschsprung's disease. SeminNeonatol2003; 8:233-41

14. Latorre-Mondrago NL, Ortega-Saldrago JA. Transanal endorectal pullthrough for Hirschsprung's disease. J padiatr surg1998; 33:1283-86

15. Langer JC, Minkes RK, Mazziotti MV.Transanal one-stage Soave procedure for infants with Hirschsprung disease. J Pediatr Surg. 1999; 34:148-52

16. Georgeson KE, Fuenfer MM, Hardin WD. Primary laoparoscopic pull through for Hirschsprung's disease in infant and children. J padiatrsurg 1995; 30:1017-22

17. Levitt M A,Miller $C$, Hamrick B E,Andrea B, Jennifer $H$, Peña A. Transanal full-thickness, Swenson-like approach for Hirschsprung disease. Journal of Pediatric Surgery2013;48: 2289-95

18. Leily M., Ahmed KT, Mohsen R, Ali RM ,Naser S, Javed G, Fathollah R, Alireza M, \& Zahra G.Comparision between Swenson and Soave pull through in Hirschprung disease. Ann colorectal Res. 2015; 3(4): e 32700

19. Coran AG, TeitelbaumDH,Recent advances in the management of Hirschsprung disease. Am J Surg2000;180:382-87

20. Gad EL-Hak NA, El- Hemaly MM, Negm EH, El-Hanafy EA,Abdel Messeh MH,Abdel Bary HH.Functional outcome of Swenson's operation for Hirschsprung disease. Saudi ] Gastroenterol2010;16:30-34

21. Holschneider AM, Kraeft $H$, Scholtissek C.Urodynamic investigation of bladder disturbances in imperforate anus and Hirschsprung's disease. Z Kinderchir2000;35:64-68

22. Fonkalsrud E.W. Complication of Hirschsprung's disease and allied disorders. In: Holschneider, AM., Puri, P.(eds).Hirschsprung's disease and allied disorders. Harwood, Singapore2000;2:425-31

23. Zhang SC., Bai Y.Z., Wang W. Long-term outcome, colonic motility, and sphincter after Swenson's procedure for Hirschsprung's disease: a single-center 2- decade experience with 346 cases. Amer J Surg.2007;194: 40-4724. Sherman J0,Snyder ME,Weitzman JJ, Jona JZ, Gillis DA, $\mathrm{O}^{\prime}$ Donnell $\mathrm{B}$, et al. A 40 years multinational retrospective study of 880 Swenson procedures. J pediatr Surg1989;24:833-38

25. Madonna MB, Luck SR, Reynolds M,Schwarz DK,Arensman RM, Swenson procedure for the treatment of Hirschsprung's disease.Semin Pediatr Surg 1998;7:85-88 